University of Nebraska - Lincoln

DigitalCommons@University of Nebraska - Lincoln

$9-1972$

\title{
Measurements of Aerosol Size Distributions and Vertical Fluxes of Aerosols on Land Subject to Wind Erosion
}

Dale A. Gillette

Irving H. Blifford Jr.

Charles R. Fenster

Follow this and additional works at: https://digitalcommons.unl.edu/usdaarsfacpub

This Article is brought to you for free and open access by the U.S. Department of Agriculture: Agricultural Research Service, Lincoln, Nebraska at DigitalCommons@University of Nebraska - Lincoln. It has been accepted for inclusion in Publications from USDA-ARS / UNL Faculty by an authorized administrator of DigitalCommons@University of Nebraska - Lincoln. 


\title{
Measurements of Aerosol Size Distributions and Vertical Fluxes of Aerosols on Land Subject to Wind Erosion ${ }^{1}$
}

\author{
Dale A. Gillette and Irving H. Blifford, JR. \\ National Center for Aimospheric Research, ${ }^{2}$ Boulder, Colo. \\ and Charles R. Fenster \\ Scotts Bluff Experiment Station, The University of Nebraska, Lincoln
}

(Manuscript received 17 February 1972, in revised form 2 June 1972)

\begin{abstract}
To assess wind erosion as a source of atmospheric soil particles, vertical aerosol fluxes near the ground in an eroding field were computed by assuming a vertical transport mechanism similar to that for momentum. Aerosol gradients were measured by jet impactors located 1.5 and $6 \mathrm{~m}$ above the ground, and wind velocity gradients were measured by totalizing-three-cup anemometers located $1.5,3$ and $6 \mathrm{~m}$ above the ground. Information on the aerosol size distributions and quantity in the size range $0.3 \leqslant r \leqslant 6 \mu \mathrm{m}$ was obtained for a variety of erosive conditions in a field in rural Nebraska. In general, the size distributions in this range suggest the power law, $d N / d(\log r) \propto r^{-2}$ for $1 \leqslant r \leqslant 6 \mu \mathrm{m}$, and a flatter curve for $0.3 \leqslant r \leqslant 1 \mu \mathrm{m}$. The relation of the aerosol size distribution in the range $0.3 \leqslant r \leqslant 6 \mu \mathrm{m}$ to the size distribution of soil was determined. Averaged soil size distributions characteristic of the sampling field, the area within a six-mile radius of the sampling field, and soil flowing (creeping) at ground level at the sampling site were found to be nearly identical. In addition, the size distribution curves for all three samples showed a general form in the ranges $0.3 \leqslant r \leqslant 1 \mu \mathrm{m}$ and $1 \leqslant r \leqslant 6 \mu \mathrm{m}$ which could be basically characterized by the same power laws as those suggested by the aerosol size distributions. Horizontal soil particle fluxes were measured and compared to the vertical fluxes. In addition, the measured erosion was compared to erosion predicted by an empirical formulation based on the parameters of soil moisture, field length, vegetative residue, mechanical stability, ridge roughness, and vertical momentum flux. These predictions agreed qualitatively with observed horizontal soil movement and with the observed vertical flux measurements. Measurements of aerosol size distributions from ground level to $11.9 \mathrm{~km}$ on two occasions when soil was very moist and no vertical flux of aerosol was observed showed the aerosol size distribution to be constant in shape and in concentration from the ground to the top of the mixing layer. Above the mixing layer, concentration decreased for all particle sizes above the mixing layer up to the base of the tropopause where an increase in concentration for the smallest particles and a decrease in concentration for the largest particles were observed.
\end{abstract}

\section{Introduction}

Although soil erosion by the wind is recognized as an important mechanism for aerosol production, there has been relatively little study of this source of aerosols. In an inventory of the global sources of tropospheric aerosols by Hidy and Brock (1970), it was estimated that dust rise by wind contributes $9.3 \%$ of the total mass of aerosols, based upon an estimate of Judson (1968), or $21 \%$ of the total mass if source estimates are adjusted to known aerosol composition.

The meteorology of dust storms has been studied by several authors (e.g., El-Fandy, 1940; Danielsen, 1964), and a considerable body of information exists on the physics of wind erosion and its control (e.g., Bagnold,

\footnotetext{
${ }^{1}$ Published as Paper No. 3403, Journal Series, Nebraska Agricultural Experiment Station.

2 The National Center for Atmospheric Research is sponsored by the National Science Foundation.
}

1941; Chepil and Woodruff, 1963). However, the erosion work is not directly applicable since it was formulated to express a mass flux of soil particles through a surface perpendicular to the ground and wind whereas the study of soil erosion as an aerosol source is concerned with the flux of soil particles through a surface parallel to the ground. The size distribution of aerosols originating as soil has been studied by El-Fandy (1953), Chepil (1957a), Chepil and Woodruff (1957), and Schuetz (1971). The work of Schuetz gives size distributions of local soils and of aerosols collected during Libyan sandstorms in sufficient detail for comparison.

In the light of information on and models of aerosol modification in the atmosphere, our investigation was undertaken on mechanisms governing the input of soil aerosols in an attempt to elucidate the life cycle of this important aerosol component. 
The objectives of this introductory study were:

1) To investigate the size distribution of aerosol measured in a field subject to wind erosion but remote from other sources of aerosol. Of particular interest was aerosol originating from the field.

2) To investigate the quantity of aerosol originating from a particular eroding parcel of land for differing conditions of wind and soil. In particular, it was desired to compare measured vertical aerosol fluxes with empirically predicted erosion.

\section{Experimental methods and instrumentation}

Since we were interested in an eroding field as a source of aerosols, we wanted to measure the vertical flux of aerosols. The aerosol and momentum flux (assumed constant in the layer within a few tens of meters from the ground) may be expressed, respectively, by

$$
\begin{gathered}
F_{A}=-K_{A} \rho \frac{\partial n}{\partial z} \\
\tau=K_{M} \rho \frac{\partial u}{\partial z}
\end{gathered}
$$

(the latter after Priestley, 1959) where $F_{A}$ is the vertical aerosol flux (positive when described upwards), $K_{A}$ the coefficient of exchange for aerosols, $\rho$ the density of air, $z$ height, $n$ the number of particles per gram of air, $\tau$ the vertical momentum flux, $K_{M}$ the eddy viscosity, and $u$ the mean horizontal velocity.

Because we were concerned with aerosols of radius $\leqslant 10 \mu \mathrm{m}$, the terminal velocity was much less than the vertical velocity fluctuations and the approximation $K_{A}=K_{M}$ was made. Therefore,

$$
F_{A}=-\tau \frac{\partial n}{\partial u}
$$

or

$$
F_{A}=-\tau \frac{\Delta n}{\Delta u}
$$

where $\Delta n$ and $\Delta u$ may be determined by measurements at heights $z_{1}$ and $z_{2}$, and $\tau$ was determined by

$$
\tau=\rho C u_{1}^{2},
$$

where $C$ is the drag coefficient (Priestley, 1959). Since $C$ changes little with Richardson number near the ground, it was determined during neutral thermal conditions as

$$
C=\frac{(0.4)^{2}}{\left[\ln \left(z_{2} / z_{1}\right)\right]^{2}}\left[\left(\frac{u_{2}}{u_{1}}\right)^{2}-\frac{2 u_{2}}{u_{1}}+1\right] .
$$

Therefore, for aerosol and wind measurements taken at heights $z_{1}$ and $z_{2}$, the flux of aerosol was

$$
F_{A}=\frac{-\rho C u_{1}^{2}\left(n_{2}-n_{1}\right)}{u_{2}-u_{1}} \text {. }
$$

In practice, aerosols within the size range $0.3 \leqslant r \leqslant 6 \mu \mathrm{m}$ were measured with respect to size and the above equation was used for each of the measured size classifications. The resulting particle fluxes as functions of size were expressed in the conventional $d N / d \log r$ $\left[\mathrm{cm}^{-2} \mathrm{sec}^{-1}\right]$ where $N(r)$ is the total number of particles having radii $\leqslant r$.

The wind speed was measured at heights above the ground of $1.5,3$ and $6 \mathrm{~m}$, and aerosols were collected by jet impactors which sampled isokinetically at heights of 1.5 and $6 \mathrm{~m}$. Three 3-cup Belfort totalizing anemometers were used for average wind measurements during the aerosol sampling. Sampling times ranged from $30 \mathrm{~min}$ to $2 \mathrm{hr}$.

The single-stage jet impactors collected the aerosol and the aerosol counts were made as described by Blifford and Ringer (1969). Briefly, the impactors were of the design described by Chagnon and Junge (1965) and were calibrated with regard to collection efficiency with radioactive aerosols. The impactor collector surface was a microscope cover slip coated with filtered silicone oil and mounted on a standard microscope slide. Size distributions of collected aerosols were determined from photomicrographs of the particles using a Zeiss TGC-3 particle sizer and counter.

Other soil erosion measurements were made simultaneously with the measurement of vertical particle fluxes. Soil particles creeping along the surface were collected with a container similar to Bagnold's (1941), a 15-cm long cylinder with an inside diameter of $3.8 \mathrm{~cm}$, buried flush with the soil surface. Soil creep was measured as mass of soil material rolling through a surface perpendicular to the ground and to the wind having a width equal to the diameter of the cylinder per unit time. To measure the total soil flow [including soil creep and saltation (bouncing along the direction of flow)], a modified Bagnold catcher, described in detail by Chepil (1957b) was used. A 1-cm wide by $80-\mathrm{cm}$ high slit was directed into the wind by a wind vane pivoted on a support in the collector bucket buried flush with the ground. The slit acted as a collecting area perpendicular to the ground and to the wind.

Parameters representative of soil condition were also measured. Soil water content was measured by drying previously air-tight containers of soil at $120 \mathrm{C}$ until three successive weights of the soil were the same. Soil cloddiness (agglomeration) was indicated by the weight percentage of the soil not passing through a rotary sieve with $0.84-\mathrm{mm}$ square openings turned at a rate of two turns per five seconds for five turns (Chepil, 1952). Mechanical stability of clods, the resistance of a dry clod to breakdown by mechanical agents such" as tillage, force of wind, and abrasion from windborne materials, 
TABLE 1. Standard deviations (percent) from independent size distribution determinations from the same aerosol collection in the laboratory and from independent size distribution determinations from two identical impactors sampling simultaneously at the same field location.

\begin{tabular}{lcccr} 
& \multicolumn{2}{c}{ Size range $(\mu \mathrm{m})$} & $1.1<r \leqslant 2.5$ & $2.5<r<6$ \\
\hline Laboratory repeatability & $0.1<r \leqslant 0.4$ & $0.4<r \leqslant 1.1$ & 12 & 62 \\
Field repeatability & 27 & 36 & 7 & 40 \\
Estimated deviation & 24 & 36 & 31 & 62 \\
\hline
\end{tabular}

was determined using the rotary sieve. Soil aggregates $>0.84 \mathrm{~mm}$ diameter remaining in the sieve after five turns were expressed in percentage of total soil. Crop residues were determined by measuring three samples of the actual amount of surface residue on 1/5000 of an acre (U.S.D.A. Committee, 1962). Ridge roughness was estimated from photographs prepared by Chepil and Woodruff (1954).

Comparison of aerosol size distributions with size distributions of soil whose aggregates were dispersed similarly to dispersal by wind erosion was desired. ${ }^{3}$ Mixtures of surface soil samples which were integrations of contributions of soils over large areas were used as the soil samples whose size distributions were determined. Size distributions of these soil mixtures were determined by wet-sieving and scanning electron microscopy. Each approximately $10-\mathrm{gm}$ soil mixture was immersed in $20 \mathrm{ml}$ of deionized water and agitated for $5 \mathrm{~min}$ in an ultrasonic shaker. The $20 \mathrm{ml}$ of soil suspension was then passed through 100-, 200-, 325- and 400 -mesh SPEX sieves. The material in each sieve was flushed with more water until no visible sediment was present in the effluent water, and the entire nest of sieves was again flushed with water for an additional $30 \mathrm{~min}$. All the water passing through the sieves, i.e., containing the particles not collected by the sieves, was allowed to stand for $24 \mathrm{hr}$. The water with suspended soil particles was poured off, and the remaining sediment was again suspended in a measured quantity of deionized water. Two slides were prepared by depositing $10 \mu \mathrm{l}$ of each suspension on the coverslip of each slide, which had been treated with a wetting agent, and allowing the slides to dry. The slides were coated with a $0.015-\mu \mathrm{m}$ layer of Au-Pd and then scanned at various magnifications by a Materials Analysis Corporation scanning electron microprobe. The particle images, superimposed upon a $80 \times 100$ grid were automatically analyzed for radial size by a method similar to that of Byers et al. (1971). These size distribution data were combined with the sieve data, which were converted to number densities by dividing the dry particle weight in each sieve by the bulk density times the volume of the median-size particle in the individual sieve. A second set of size distributions was obtained using the microscope slides and the optical microscopic

${ }^{3}$ The authors are grateful to M. L. Jackson of the University of Wisconsin Department of Soil Science who suggested the following dispersal technique. method used by Blifford and Ringer (1969). The size distributions from the optical microscope method agreed with the distributions obtained with the electron microprobe.

\section{Error analysis}

Since the difference between two simultaneously obtained aerosol size distributions was used in determining the aerosol flux, the variability of each size distribution determines the sensitivity of the technique. The simplest source of error, the counting error, may be expressed in percentage by the Poisson distribution formula

$$
\sigma=100 / \sqrt{N}
$$

where $\sigma$ is the standard deviation (\%) and $N$ the total number of particles counted. Variability resulting from the laboratory procedure was determined by examining the results for laboratory repeatability. Two independent determinations were made on three aerosol collections, and the percentage standard deviations for the four size classes used in the field data are given in Table 1. Also given in Table 1 are the standard deviations of results which should be the result of all sources of variability. Two identical impactors were operated simultaneously side by side in the field, and independent size distributions were determined for each set of impactor data. The percentage standard deviations of the impactor data were roughly equal to the percentage standard deviations of the laboratory repeatability tests. The last line of Table 1 gives the estimates of error used for the field samples which correspond to the larger of percentage standard deviations for the laboratory and field repeatability tests except for the size range $1.1<r \leqslant 2.5 \mu \mathrm{m}$ which was assigned the average deviation for all size ranges.

\section{Results}

\section{a. Samples showing a vertical flux of aerosol}

All samples were taken at heights of 1.5 and $6 \mathrm{~m}$ above the ground in an eroding field at the University of Nebraska Northwest Experimental Laboratory located near Alliance, Nebr. Vertical aerosol fluxes were detected in samples 1 and 2 (taken on 17 March 1971 at 1200 and 1300 CST), sample 5 (1 April 1971, 1200 CST), and sample 7 (5 April 1971, 1100 CST). In Fig. 1 these 

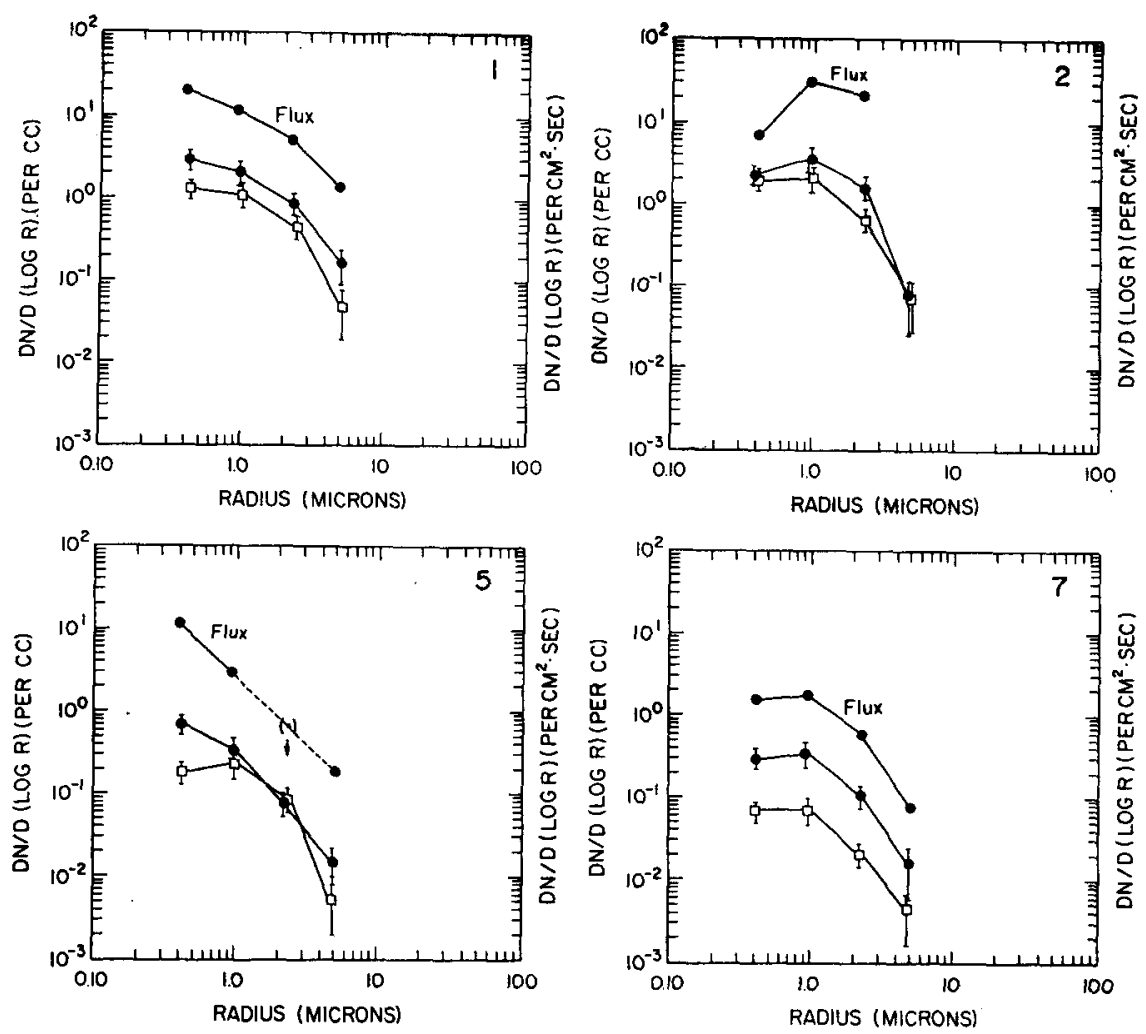

FIG. 1. Aerosol size distributions obtained when a vertical aerosol flux was detected. Size distribution of the vertical flux of aerosols is given with the units at the right border with absolute number given at the left border. Sample number is given in the upper righthand corner. Squares designate $6 \mathrm{~m}$ and dots designate $1.5 \mathrm{~m}$.

fluxes and the size distributions are shown using the conventional $d N / d \log r$ notation explained earlier. Samples 1 and 2 were taken at the beginning of a prefrontal dust storm when the wind velocity at $1.5 \mathrm{~m}$ was 4.19 and $10.6 \mathrm{~m} \mathrm{sec}^{-1}$, respectively. The size distribution of the flux of aerosols for sample 1 is similar to the size distribution of the aerosol at both heights. Although the size distributions at each height were similar, the size distribution of the flux of aerosols for sample 2 differs, probably because of abrasion of the impactor slide by the increasing concentration of sand $(r>50 \mu \mathrm{m})$ particles noticed at the time of the aerosol collection at $1.5 \mathrm{~m}$. The wind velocity increased after the two samples were taken, and the dust content of the air became much greater. Unfortunately, the collection equipment became clogged with the high density aerosol, and no meaningful samples could be salvaged. Sample 5 was taken when the wind velocity was quite high $\left(11.6 \mathrm{~m} \mathrm{sec}^{-1}\right.$ at $\left.1.5 \mathrm{~m}\right)$ but when the soil had been hardened into a surface crust approximately $2 \mathrm{~cm}$ thick. The flux on this day was somewhat smaller than those of samples 1 and 2 even though wind velocity was actually greater, which shows the importance of soil condition. Sample 7 was taken when the wind velocity was much less than on the other days when vertical fluxes occurred. It was noticed, however, that during the sampling time plowing was taking place about $100 \mathrm{~m}$ upwind, and an invisible artificially stimulated flux of dust was measured.

For those measurements when a vertical flux was deduced, the shapes of the aerosol size distributions were remarkably similar, and consequently the size distribution of the vertical aerosol flux was similar to the size distribution of the aerosol at either 1.5 or $6 \mathrm{~m}$. Indeed, the size distribution for all samples might be characterized by $d N / d \log r \propto r^{-2}$ for the size range measured $(1 \leqslant r \leqslant 6 \mu \mathrm{m})$ and by a flatter slope for $r<1 \mu \mathrm{m}$.

The flux figures given for $d N / d \log r$ were converted to mass flux $\mathrm{cm}^{-2} \mathrm{sec}^{-1}$ by using the bulk density of $2.4 \mathrm{gm} \mathrm{cm}^{-3}$ determined for the soil creep sample of 17 March 1971. The average of the fluxes measured on

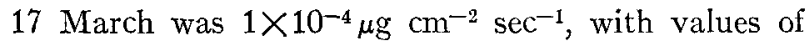
$0.9 \times 10^{-5}$ and $0.6 \times 10^{-5} \mu \mathrm{g} \mathrm{cm} \mathrm{cm}^{-2} \mathrm{sec}^{-1}$, respectively, on 1 and 5 April. Data giving mass of dust with height along with wind velocity ${ }^{4}$ (Chepil, 1957a) were examined for the possibility of computing vertical fluxes. Since the drag coefficient had not been determined, data sets were chosen for which the wind speed followed a

\footnotetext{
${ }^{4}$ The authors are grateful to N. Woodruff for kindly allowing us to examine the original data of this publication.
} 
logarithmic profile. Fluxes were determined by the formulation of Section 2 except that

$$
\tau=\rho \frac{(0.4)^{2}(\Delta u)^{2}}{\left(\begin{array}{c}
\ln _{2} \\
z_{1}
\end{array}\right)^{2}} \text {. }
$$

Estimated values for vertical aerosol fluxes taken in well-developed dust storms ranged from 0.07 to $21 \mu \mathrm{g}$ $\mathrm{cm}^{-2} \mathrm{sec}^{-1}$. These values are much higher than those of our experiments but cannot be regarded as more than rough approximations. They are probably overestimates since the assumption of negligible fall velocity compared to vertical motion of the air is probably not true for these samples which measured total mass of the dust and which were not restricted to the limited size range measured by the present study. The samples of the present study were taken at the beginnings of dust storms, not in well-developed dust storms, and show expected lower concentrations.

\section{b. Samples showing no vertical flux of aerosol}

Pairs of size distribution samples whose differences are less than the standard deviations explained above are shown in Fig. 2. Most of the experiments for which zero flux was determined were repeated at least twice. Results taken successively under the same conditions were essentially identical in size distribution shape and flux, however, so that only one set of size distribution results are presented for a given day. These samples in
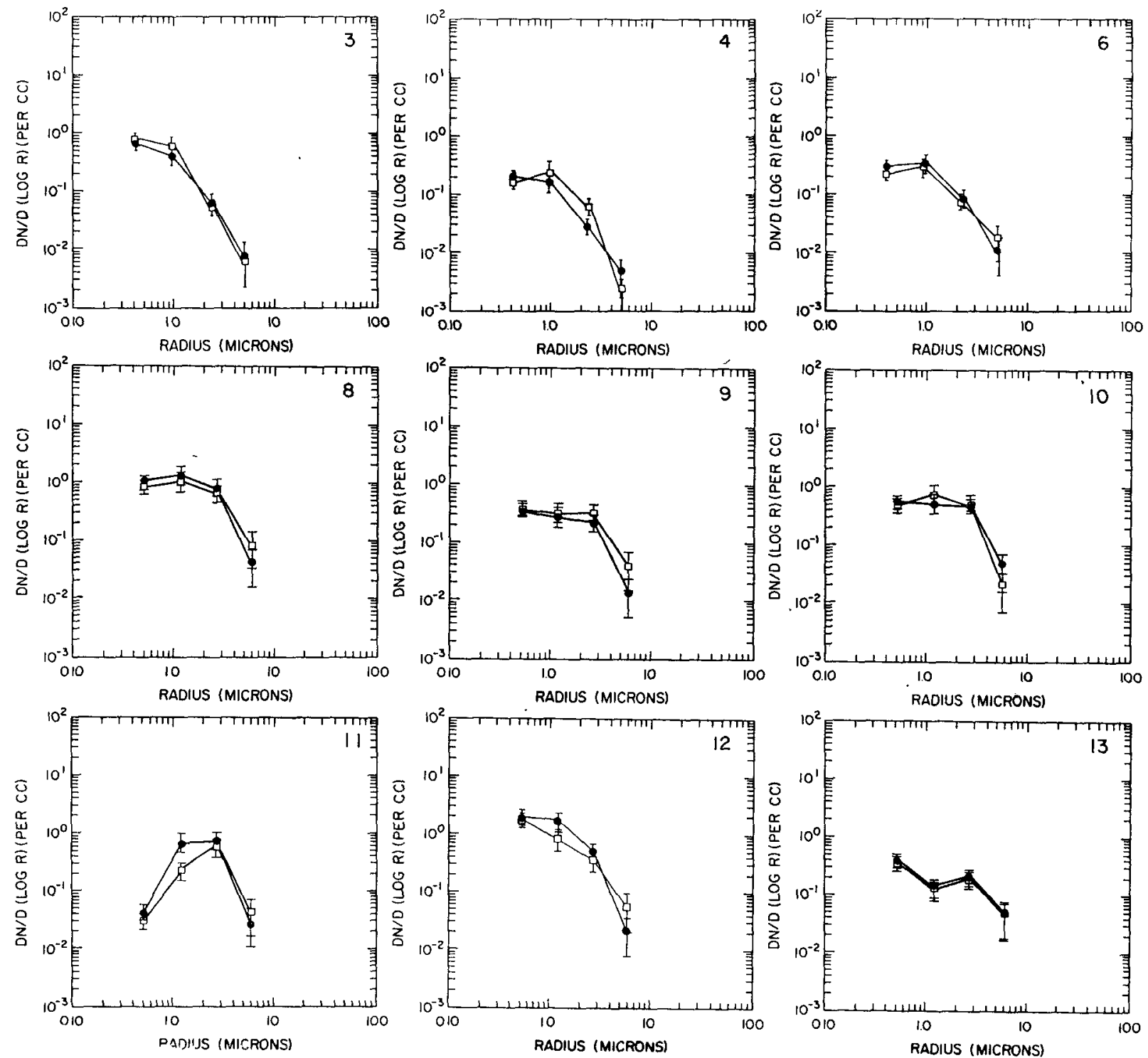

Frg. 2. Aerosol size distributions obtained when a vertical flux of aerosol was not detected. Sample number is in the upper righthand corner. Squares designate $6 \mathrm{~m}$ and dots designate $1.5 \mathrm{~m}$. 
TABLE 2. Soil particle diameters and water content at several tensions for a Kieth sandy loam soil on which the aerosol experiment was located.

\begin{tabular}{|c|c|c|c|c|c|c|c|c|}
\hline $\begin{array}{l}\text { Sample } \\
\text { !no. }\end{array}$ & $\begin{array}{c}\text { Organic } \\
\text { matter } \\
\text { by mass } \\
\text { (percent) }\end{array}$ & $\begin{array}{c}\text { Sand } \\
>50 \mu \mathrm{m} \\
\text { diameter }\end{array}$ & $\begin{array}{l}\quad \text { Percen } \\
\text { Coarse silt } \\
20-50 \mu \mathrm{m} \\
\text { diameter }\end{array}$ & $\begin{array}{l}\text { age of } \\
\text { Fine silt } \\
2-20 \mu \mathrm{m} \\
\text { diameter }\end{array}$ & $\begin{array}{c}\text { Clay } \\
<2 \mu \mathrm{m} \\
\text { diameter }\end{array}$ & \multicolumn{3}{|c|}{$\begin{array}{c}\text { Percent water content at } \\
\text { tensions of }\end{array}$} \\
\hline $\begin{array}{c}1 \\
2 \\
\text { Average }\end{array}$ & $\begin{array}{l}1.01 \\
0.77 \\
0.89\end{array}$ & $\begin{array}{l}65.0 \\
65.0 \\
65.0\end{array}$ & $\begin{array}{r}5.5 \\
14.3 \\
9.9\end{array}$ & $\begin{array}{r}15.8 \\
7.0 \\
11.4\end{array}$ & $\begin{array}{l}13.7 \\
13.7 \\
13.7\end{array}$ & $\begin{array}{l}11.9 \\
12.4 \\
12.2\end{array}$ & $\begin{array}{l}8.4 \\
8.2 \\
8.3\end{array}$ & $\begin{array}{l}5.9 \\
5.9 \\
5.9\end{array}$ \\
\hline
\end{tabular}

general were taken on days of lower wind velocities and higher soil moisture. Sample 3 was taken on a day (18 March 1971, 1400 CST) when the entire Nebraska Panhandle area was covered by snow. The great similarity of the two size distributions agrees with the absence of soil aerosols rising from the ground. Sample 6 was taken on 4 April 1971 at 1500 hours when there were light winds and when the top $2 \mathrm{~cm}$ of the soil was was crusted. Sample 4 was taken during a day of high winds (31 March 1971, 1000 CST), but the soil was held by a strong crusted structure in the top $2 \mathrm{~cm}$, and the soil moisture was barely greater than the " 15 atmosphere percentage soil moisture."5 Sample 8 was taken 13 May 1971, 1400 CST, when wind velocity was quite low and the soil was quite moist as a result of about $10 \mathrm{~cm}$ of rainfall during the week preceding the sampling. Samples 9-11 were taken on 28, 29 and 30 April at 1300,1100 and $1100 \mathrm{CST}$, respectively, when wind velocities were low and soil moisture was quite high. The size distributions of 28 and 29 April, as well as the non-flux size distributions mentioned above, are similar in shape to the size distributions taken when vertical aerosol flux was determined. The size distribution for 30 April, however, shows a much lower concentration of particles with $r<1 \mu \mathrm{m}$ than the previous size distributions. This possibly reflects the wet condition of the soil over a wide area around the field and a thermal inversion at $1.5 \mathrm{~km}$, recorded shortly before the aerosol sample was collected, which may have isolated the lowest layers from aerosol advected at higher altitudes. Sample 12 (15 April, 1200 CST) was taken when soil moisture was quite low but wind velocity was also quite low. The form of the aerosol size distribution resembles more the form of the flux aerosol size distribution than that of sample 11. Sample 13 was taken on 12 July 1971 (1200 CST) when the field was in full growth with a $60-\mathrm{cm}$ stand of wheat. The shape of the size distribution on this day reflects the presence of biological particles ${ }^{6}$ with radii larger than $1 \mu \mathrm{m}$.

Erosion conditions such as soil moisture, wind velocity, and cloddiness of the soil varied widely for the samples. The vegetative-residue and ridge-roughness

\footnotetext{
${ }^{5}$ The percentage of water contained in the soil that has been saturated, subject to, and in equilibrium with, an applied pressure of $15 \mathrm{~atm}$.

6 The authors are grateful to Profs. James Rosowski and Wendell Gauger of the University of Nebraska Department of Botany who identified many genera of plant cells in the aerosol collection of July 12 .
}

parameters were constant for all experiments since all the samples were taken in the same field. The field length in the direction of the wind was almost constant since almost all samples were taken when the wind was from the northwest. Soil moisture varied from a minimum of $2.5 \%$ on 15 April (sample 8 ) to a maximum of $19.4 \%$ on 28 April (sample 9). Soil clods larger than $0.84 \mathrm{~mm}$ in diameter ranged from $54 \%$ on 1 April when a rather strong crust was observed on the surface to $29 \%$ on 17 March when the soil, which previously had been abraded by a dust storm, did erode.

\section{c. Physical properties of the soil}

Two soil samples were collected from the area to the northwest of the tower where most of the wind erosion occurred during the study. Each sample was a composite of 10 cores representative of soil to a depth of 4 inches. Organic matter was determined by the University of Nebraska Soil Testing Laboratory and the particle size analyses and water tensions in the Soil Physics Laboratory. Results are given in Table 2.

Particle size (diameter) was determined by the Buoyocous (1951) method, the soil textural classification by the chart designed by Baver (1956), and the soil moisture tension by the method designed by Richards (1949). Organic matter was determined by the Walkley (1947) method as modified by Smith and Weldon (1949).

\section{d. Size distributions of soils}

Three mixtures of soil representative of averages of surface soils in three areas (Jackson, 1958) were analyzed for size distribution. The mixtures were as follows:

1) Six soil samples taken within a $19-\mathrm{km}$ radius of the sampling location. These soil samples were representative of all the major soil types within the area and were mixed in the proportions in which each soil type was estimated to be present in the area. ${ }^{7}$

2) Thirty soil samples obtained within a $30 \mathrm{~m}$ radius of the sampling tower. These soil samples were equally spaced within the area and were mixed in equal proportions.

${ }^{7}$ The authors are grateful to Mr. Dale Gengenbach, U.S.D.A. Soil Conservationist, for obtaining the soil samples and $\mathrm{Mr}$. Rudolph Hraban, Area Conservation Officer, for support in obtaining the soil samples. 


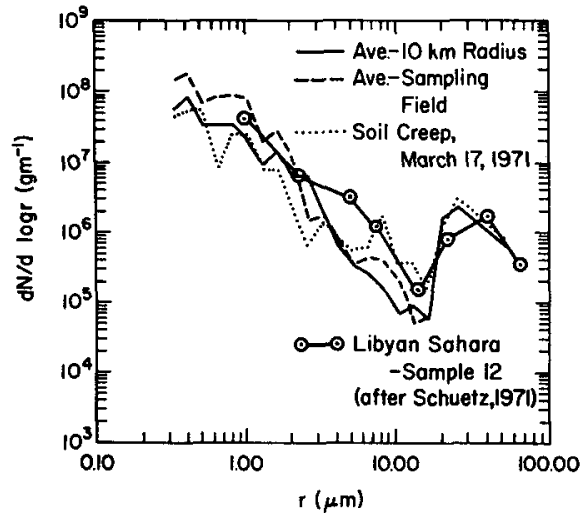

Fig. 3. Size distributions of three mixtures of soil representative of soils within a $10-\mathrm{km}$ radius of the sampling tower, soils within a $10-\mathrm{km}$ radius of the sampling tower, and a soil creep sample obtained within $3 \mathrm{~m}$ of the tower on 17 March 1971. A size distribution of Sahara soil obtained by Schuetz (1971) is shown for comparison.

3) A sample of "soil creep" obtained within $2 \mathrm{~m}$ of the sampling tower on 17 March 1971. This soil, representative of soil actually eroding and available to become aerosol, was an integrated mixture of soils from an area larger than that used in taking a single soil sample.

Size distributions for the three soil mixtures are shown in Fig. 3. Striking similarities are seen in the three distributions, especially for sizes where most of soil mass is found $(r>20 \mu \mathrm{m})$. A secondary maximum is seen in the distributions at around $r=50 \mu \mathrm{m}$ where the coarse portion of the soil is contained. For particle radii less than $10 \mu \mathrm{m}$ and greater than $1 \mu \mathrm{m}$, the size distributions may be roughly characterized by $d N / d \log r \propto r^{-2}$. The general features of these soil distributions agree quite well for $r>1 \mu \mathrm{m}$ with the soil size distributions of Schuetz (1971) for soil samples collected in the Libyan
Sahara. In addition, the size distributions of the soil samples and the size distributions of the aerosols are similar in shape for the size range in which the aerosol size distributions were determined. Of course, the authors do not claim that the wet sieving and suspension settling techniques duplicate the soil dispersion processes which operate during soil erosion. It is probable that size distribution is dependent upon erosion parameters, especially the mechanical aggregate structure of the soil.

The flattening of the size distributions for particles $<1 \mu \mathrm{m}$, implying less than $0.1 \%$ of soil mass for $0.3 \leqslant r \leqslant 1 \mu \mathrm{m}$, may seem to be in disagreement with the figure of $13.7 \%$ by mass of soil particles being clay $(r<1 \mu \mathrm{m})$. However, a difference in the dispersion technique (i.e., using a detergent to obtain an ultimate separation of small clay particles from larger soil particles by the University of Nebraska) explains the discrepancies. Indeed, the similarities of our obtained soil size distributions and the aerosol size distributions would imply that a small fraction of the submicron soil particles (in this case less than $0.8 \%$ ) are available as free particles to constitute the submicron part of the aerosol. This relative lack of small particles is supported by consideration of the large amount of force required to separate dry clay particles from agglomeration compared with that for larger particles (Smalley, 1970). Such force is probably not available for most cases in the abrasion of soil during wind erosion.

A photomicrograph of cross sections of silt- and sandsized particles (Fig. 4) in a 30- $\mu \mathrm{m}$ standard commercially prepared "thin section" of the untampered soil creep sample collected on 17 March during a dust storm shows a coating of submicron clay particles on the surface of the larger particles. Calculations using the size distribution of soil collected in the sampling field
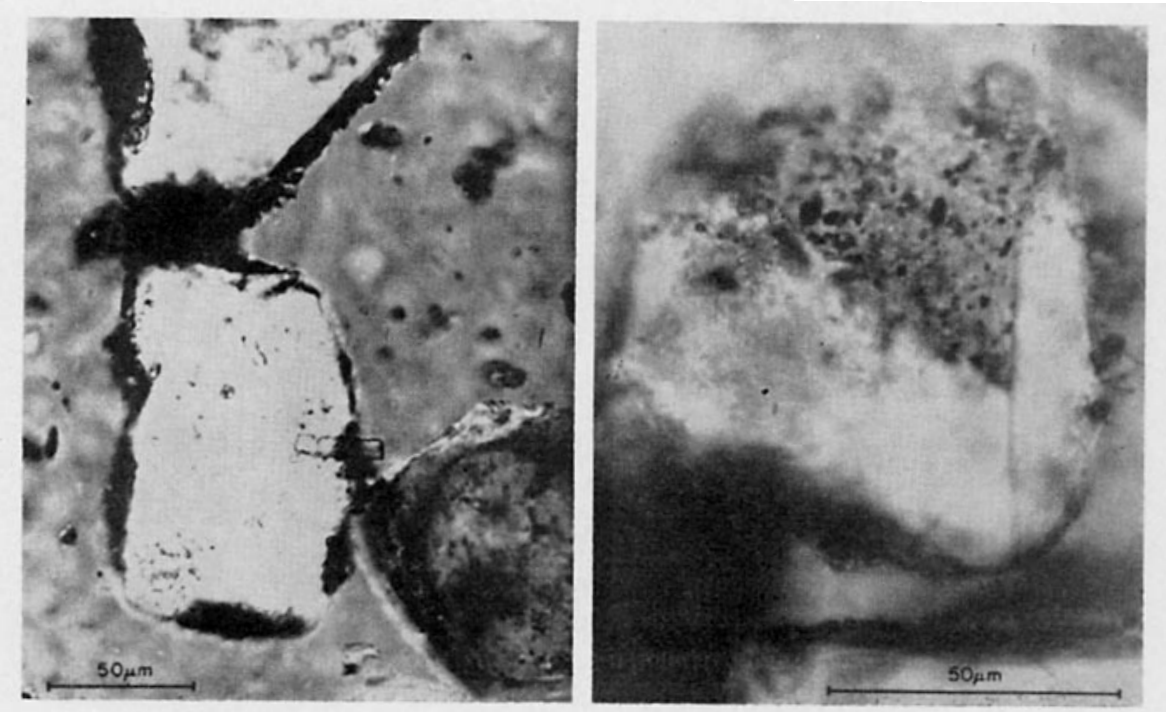

FrG. 4. Photographs of $30-\mu \mathrm{m}$ soil thin sections in polarized light showing soil particles in cross section coated with submicron particles (clay). 
showed that if the $13.7 \%$ by mass of soil particles in the clay classification were of uniform $1 \mu \mathrm{m}$ radius and spherical, their cross-sectional area would be about 23 times the surface area of the particles $>1 \mu \mathrm{m}$. Since this is probably an underestimate of the cross-sectional area of the submicron particles, it would seem likely that the clay particles form coatings several layers thick. The soil thin section showed that independent submicron particles were only slightly more numerous than particles $>10 \mu \mathrm{m}$ and that clay coatings were present on virtually all visible particles detected to the limit of resolution of the microscope. The failure of the wind erosion mechanisms to totally disintegrate the agglomeration of soil particles determines the relative lack of particles $<1.0 \mu \mathrm{m}$. Thus, aerosol derived from soil has a size distribution which seemingly follows the size distribution of the soil except for $r<1 \mu \mathrm{m}$ where soil agglomeration is effective and for $r>10 \mu \mathrm{m}$ where gravitational sedimentation effectively removes particles from the air.

\section{e. Direct measurement of soil flow}

Direct measurement of horizontal soil flux was accomplished by adding the flow collected by the soil creep container and the Bagnold catcher which was set slightly above ground level in order not to collect soil creep. The flow is expressed in terms of grams of soil per centimeter width per second and is given in Table 3 corresponding to the soil flux samples. The flow corresponding to samples 1 and 2 was measured only by soil creep containers and therefore represents an underestimate of the total soil flow. When less than $0.1 \mathrm{gm}$ of soil was collected over the sampling period (typically several hours), the flux was set to zero since disturbance of the soil caused by the installation of the soil creep collector could account for this amount. There is good qualitative agreement between observation of vertical flux of aerosols and the horizontal flux.

\section{f. Comparison of soil flow to empirical erosion formulation}

Parameters used in an empirical "erosion equation" were determined so that comparison between vertical aerosol fluxes and predicted horizontal soil fluxes could be made. The formulation is drawn from three publications of the Wind Erosion Laboratory group at Manhattan, Kan. Briefly, an empirical formula was used to find dry soil fluxes for wind tunnel conditions and then this result was adjusted to find the flow captured by a Bagnold catcher in a field. Erosion parameters are given in Table 3. Wind tunnel erodibility for dry soil is given by Chepil and Woodruff (1959) as

$$
X=3302 \frac{I}{(R K)^{1.26}},
$$

where $X$ is soil loss in tons per acre, $I$ a dimensionless soil-erodibility index for the percentage of surface soil material less than $0.84 \mathrm{~mm}$ in diameter (given in Table 4), $R$ the weight of surface residue in pounds per acre and $K$ the ridge roughness equivalent in inches. The ideas expressed by the equation are that soil is more erodible the less the soil is agglomerated, the less vegetative residue present, and the smaller the ridge roughness which tends to trap soil movement. The effect of soil moisture was empirically corrected for by

TABLE 3. Environmental conditions of wind and soil ${ }^{1,2,3}$, observed horizontal flux, and predicted horizontal flux of airborne soil and observed vertical flux of aerosol.

\begin{tabular}{|c|c|c|c|c|c|c|c|c|}
\hline Samples & Date $^{5}$ & $\begin{array}{l}\text { Wind speed } \\
\text { at } 1.5 \mathrm{~m} \\
(\mathrm{~cm} \mathrm{sec}-1)\end{array}$ & $\begin{array}{c}\text { Soil } \\
\text { moisture } \\
\text { (percent) }\end{array}$ & $\begin{array}{c}\text { Agglom- } \\
\text { erates } \\
>0.84 \mathrm{~mm} \\
\text { (percent) }\end{array}$ & $\begin{array}{l}\text { Mechanical } \\
\text { stability } \\
\text { (percent) }\end{array}$ & $\begin{array}{l}\text { Observed } \\
\text { horizontal } \\
\text { flux } \\
\left(\mathrm{gm} \mathrm{cm}^{-1}\right. \\
\left.\mathrm{sec}^{-1}\right)\end{array}$ & $\begin{array}{l}\text { Predicted } \\
\text { horizontal } \\
\text { flux } \\
\mathrm{gm} \mathrm{cm}^{-1} \\
\left.\mathrm{sec}^{-1}\right)\end{array}$ & $\begin{array}{c}\text { Vertical } \\
\text { flux } \\
\left(\mu \mathrm{g} \mathrm{cm}^{-2} \mathrm{sec}^{-1}\right)\end{array}$ \\
\hline $1-2$ & 710317 & 1171 & 4.3 & 29 & 76 & $0.024^{*}$ & 0.12 & $1 \times 10^{-4}$ \\
\hline 3 & 710318 & 930 & 7.4 & 43 & 68 & 0 & 0 & 0 \\
\hline 4 & 710331 & 983 & 5.2 & 40 & 70 & 0 & 0 & 0 \\
\hline 5 & 710401 & 1162 & 4.2 & 54 & 60 & 0.0001 & 0.007 & $0.9 \times 10^{-5}$ \\
\hline 6 & 710404 & 425 & 4.1 & 42 & 73 & ot & 0 & 0 \\
\hline 7 & 710405 & 134 & 4.6 & 43 & 66 & $0+$ & 0 & $0.6 \times 10^{-5} \ddagger$ \\
\hline 8 & 710415 & 349 & 2.5 & 47 & 63 & $0 \dagger$ & 0 & 0 \\
\hline 9 & 710428 & 174 & 19.4 & 41 & 57 & $0 \dagger$ & 0 & 0 \\
\hline 10 & 710429 & 353 & 7.2 & 40 & 71 & $0 \dagger$ & 0 & 0 \\
\hline 11 & 710430 & 322 & 15.6 & 35 & 79 & $0 \dagger$ & 0 & 0 \\
\hline 12 & 710513 & 245 & 9.7 & 48 & 64 & $0 \dagger$ & 0 & 0 \\
\hline $13^{4}$ & 710712 & 300 & 6.5 & 35 & 81 & $\mathrm{O}^{+}$ & 0 & 0 \\
\hline
\end{tabular}

† Less than $0.1 \mathrm{gm}$ soil was collected during the entire sampling period.

* Only soil creep was measured.

$\ddagger$ Flux caused by upwind plowing.

1 Field length was $2640 \mathrm{ft}$ for exps. 1 and 2 and $1320 \mathrm{ft}$ for the other experiments. Protected field length was $0 \mathrm{ft}$ for all experiments.

2 Vegetative cover was $300 \mathrm{lb}$ acre $\mathrm{ach}^{-1}$ for all samples except 13.

Roughness was 1 inch for all samples except 13.

4 The field was covered by a $60-\mathrm{cm}$ stand of wheat during sample 13

Dates are abbreviated in the six-digit number. The first two digits give the year, the second two the month, and the third two the day; e.g., 700101 means 1 January 1970. 
TABLE 4. Soil erodibility index $I$ based on percentage of soil fractions greater than $0.84 \mathrm{~mm}$ in diameter as determined by dry sieving (after Chepil and Woodruff, 1959).

\begin{tabular}{|c|c|c|c|c|c|c|c|c|c|c|}
\hline $\begin{array}{c}\text { Percentage of soil } \\
\text { fractions greater } \\
\text { than } 0.84 \mathrm{~mm}: \\
\text { Tens }\end{array}$ & 9 & 8 & 7 & 6 & 5 & its ${ }_{4}$ & 3 & 2 & 1 & 0 \\
\hline $\begin{array}{l}9 \\
8 \\
7 \\
6 \\
5 \\
4 \\
3 \\
2 \\
1 \\
0\end{array}$ & $\begin{array}{l}0.02 \\
0.12 \\
0.55 \\
1.1 \\
3.1 \\
6.5 \\
13 \\
25 \\
70\end{array}$ & $\begin{array}{l}0.03 \\
0.14 \\
0.60 \\
1.2 \\
3.4 \\
7.0 \\
14 \\
27 \\
80\end{array}$ & $\begin{array}{c}0.03 \\
0.16 \\
0.65 \\
1.3 \\
3.7 \\
7.5 \\
15 \\
30 \\
100\end{array}$ & $\begin{array}{c}0.04 \\
0.20 \\
0.70 \\
1.4 \\
4.0 \\
8.0 \\
16 \\
33 \\
120\end{array}$ & $\begin{array}{c}0.05 \\
0.25 \\
0.75 \\
1.6 \\
4.3 \\
8.5 \\
17 \\
36 \\
150\end{array}$ & $\begin{array}{c}0.06 \\
0.30 \\
0.80 \\
1.8 \\
4.9 \\
9.0 \\
18 \\
39 \\
175\end{array}$ & $\begin{array}{c}0.07 \\
0.35 \\
0.85 \\
2.0 \\
4.9 \\
9.5 \\
19 \\
43 \\
280\end{array}$ & $\begin{array}{c}0.08 \\
0.40 \\
0.90 \\
2.2 \\
5.2 \\
10.5 \\
20 \\
17 \\
450\end{array}$ & $\begin{array}{c}0.09 \\
9.45 \\
0.95 \\
2.5 \\
5.6 \\
11.0 \\
21 \\
51 \\
1000\end{array}$ & $\begin{array}{c}0.02 \\
0.10 \\
0.5 \\
1.0 \\
2.8 \\
6.0 \\
12.0 \\
23 \\
55 \\
-\end{array}$ \\
\hline
\end{tabular}

reducing the reference momentum flux by a quantity

$$
6\left(\frac{w}{w^{\prime}}\right)^{2}\left[\mathrm{dyn} \mathrm{cm}^{-2}\right]
$$

where $w$ is the amount of water held in soil and $w^{\prime}$ the amount of water held by the same soil at the 15 -atm percentage (Chepil, 1956). Finally, the predicted soil flow is determined by considering the field length and observed momentum flux in the formula for field length less than 16,500 ft:

$$
F=2 \frac{L X}{16,500}\left(\frac{\tau}{\tau^{\prime}}\right)^{\frac{3}{2}}
$$

where $F$ is the horizontal flux of soil in tons per rod width per hour, $L$ field length in feet, $X$ the previously determined wind tunnel erodibility, $\tau$ the observed momentum flux corrected for soil moisture as above, and $\tau^{\prime}$ the reference flux (Chepil, 1957b). The equation states that the horizontal flux increases linearly with distance downwind in a field due to the effect of "avalanching" loosening of soil due to abrasion from particles originating upwind. The term $\left(\tau / \tau^{\prime}\right)^{\frac{3}{2}}$ reflects Bagnold's (1941) formula for mass flux during sand storms.

The predicted values of horizontal soil flux are given is Table 3. Compared to observed values, the predicted values are higher. This may be partially explained on $18 \mathrm{March}$ by the fact that only soil creep was measured and not the total flux passing through a surface from the ground to $80 \mathrm{~cm}$ for which the formulation is valid. On 1 April the soil parameters were on the borderline of predicting soil erosion. That is, for the agglomeration of the soil and vertical transport of momentum, the soil moisture was slightly less than that necessary to hold the soil in place. For such a situation, slight increases in agglomeration of the soil and of soil moisture would have been sufficient to hold the soil and prevent the erosion soil flux predicted. Indeed, slight variations of soil moisture on 1 April throughout the field could have had the effect of holding the soil over much of the field and consequently preventing the full development of wind erosion which the above empirical formulation predicts. Due to the lack of data for many erosion situations, we must say that only the qualitative aspects of the erosion equation seem quite successful at this time for our purposes. When the erosion equation predicts no (some) erosion, no (some) vertical and horizontal particle fluxes were observed.

\section{g. Other measurements}

On 28 and 30 April, size distributions of aerosols were determined for various altitudes above the experimental site, and a series of radiosonde balloon releases were made to determine the thermal structure of the atmosphere. On both days, no vertical aerosol flux was detected and because of recent rain little dust rise from the entire area was expected. Radiosonde measurements indicated that the mixing layer extended to about 3.1 $\mathrm{km}$ at $1200 \mathrm{CST}$, to $3.6 \mathrm{~km}$ at 1400 , and $4.3 \mathrm{~km}$ at 1700 on 28 April. Fig. 5 shows that the aerosol size distributions had great similarity below $3.8 \mathrm{~km}$, which would indicate effective mixing and little contribution from ground sources. Above $3.8 \mathrm{~km}$ the concentration of aerosol decreases, although the sample at $11.9 \mathrm{~km}$ shows

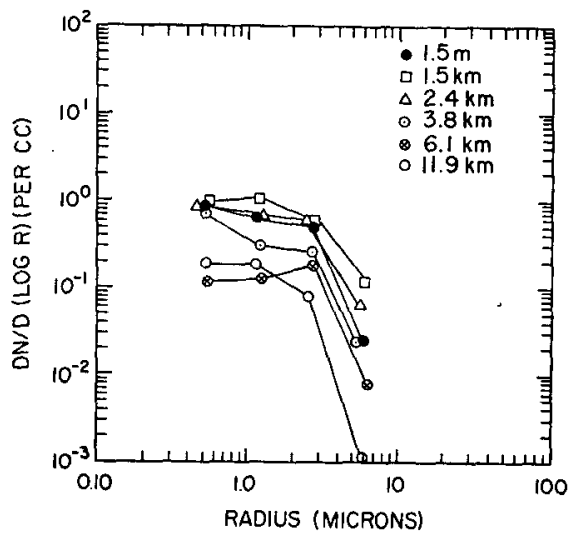

FIG. 5. Size distributions of aerosols collected above the sampling site on 28 April 1971. 


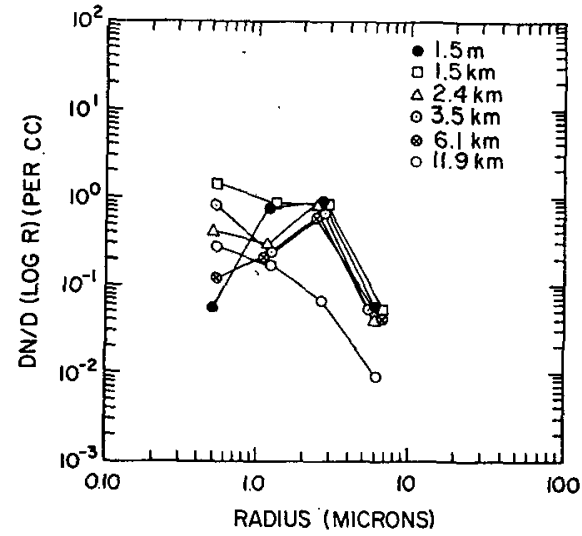

FIG. 6. Size distributions of aerosols collected above the sampling site on 30 April 1971.

a greater concentration of small particles at the smallest size class. Since the thermal data indicate that the base of the tropopause inversion was at $10.5 \mathrm{~km}$, the increase in concentration of small particles probably reflects the presence of stratospheric aerosol.

On 30 April, thermal measurements indicated that the mixing layer extended to $1.5 \mathrm{~km}$ at 0900 , to $3.6 \mathrm{~km}$ at 1200 , and to $4.2 \mathrm{~km}$ at 1500 . The ground samples were taken at 1000 and possibly reflect the low-level inversion isolating the lowest layer from advected aerosol at higher altitudes in that they show a relatively small number of particles with $r<0.8 \mu \mathrm{m}$ (Fig. 6). The particle size distributions from 1.5 to $3.5 \mathrm{~km}$ (within the mixing layer at the time of collection) are quite similar, especially for $r>1 \mu \mathrm{m}$. The size distribution at $6.1 \mathrm{~km}$ shows a reduction in concentration compared to distributions for lower altitudes. The tropopause inversion base was at approximately $11 \mathrm{~km}$, and the concentration of particles with $r<1 \mu \mathrm{m}$ again shows an increase in concentration at $11.9 \mathrm{~km}$ compared to $6.1 \mathrm{~km}$.

\section{Conclusions}

The size distribution of aerosol originating from the soil bears strong resemblance to the size distribution of the soil itself. For the size range $0.3 \leqslant r \leqslant 1 \mu \mathrm{m}$ the number of soil particles and of soil-derived aerosol particles increase slightly with decreasing radius. For the size range $1 \leqslant r \leqslant 6 \mu \mathrm{m}$ both the soil size distribution and aerosol size distribution suggest a -2 slope for the function $d N / d \log r$. A reason for such size distributions is that clay particles remain largely agglomerated to other clay particles and to larger particles. Size distributions of soil on days when no vertical flux was observed were in general similar to the size distribution of the aerosol flux. This was interpreted as reflecting dominance of soil dust as an aerosol source, with the aerosol arising far from the area where measurements were made. The dominance of soil dust in the isolated rural area in which these measurements were taken does not conflict with the "Junge law" predicting a -3 slope for continental aerosol. Indeed, in more populated regions of a continent where many sources of aerosol contribute to the total mixture of aerosol, the aerosol size distribution slope may be steepened due to 1) addition of submicron particles from sources other than soil, and 2) physical processes acting upon the aerosol to remove large particles preferentially to small particles.

Predictions of wind erosion and observed vertical aerosol fluxes were in qualitative agreement. It would appear from the calculations that soil moisture, wind velocity, roughness and vegetative residue are extremely important parameters in determining the availability of soil particles for removal on a non-vegetated piece of land.

On two days for which vertical aerosol flux was observed to be negligible in an eroding field and was inferred to be small over the entire western Nebraska area, the size distribution was quite constant in shape and magnitude in the mixing layer of the troposphere.

Acknowledgments. It is a pleasure to acknowledge the help of Dr. William Swinbank who suggested the method of measuring vertical aerosol flux and who chose the specific location of the sampling tower. The staff of the University of Nebraska Northwest Agricultural Laboratory and in particular Mr. Jason Webster helped in many practical ways and provided a field site. Mr. G. J. Dolan and the NCAR Research Aviation Facility obtained the aircraft aerosol collections. Mr. Roy Eis carried out the radiosonde measurements and the NCAR Field Observing Facility erected the observation tower. Ms. Karen Buettner and Enid Grossman carried out the laboratory procedures in obtaining the aerosol size distributions.

\section{REFERENCES}

Bagnold, R. A., 1941: The Physics of Blown Sand and Desert Dunes. London, Methuen, 265 pp.

Baver, L. D., 1956: Soil Physics. New York, Wiley, 489 pp.

Blifford, I. H., and L. D. Ringer, 1969: The size and number distribution of aerosols in the continental troposphere. $J$ : Almos. Sci., 26, 716-726.

Buoyocous, G. J., 1951: A recalibration of the hydrometer method for making mechanical analysis of soils. Agron. J., 43, 434-438.

Byers, R. L., J. W. Davis, E. White and R. McMillan, 1971: A computerized method for size characterization of atmospheric aerosols by the scanning electron microscope. Environ. Sci. Tech., 5, 517-521.

Chagnon, C. W., and C. E. Junge, 1965: The size distribution of radio-active aerosols in the upper troposphere. J. A $p p l$. Meteor., 4, 329-333.

Chepil, W. S., 1952: Improved rotary sieve for measuring state and stability of dry soil structure. Soil Sci. Amer. Proc., 16, 113-117.

, 1956: Infiuence of moisture on erodibility of soil by wind. Soil Sci. Soc. Proc., 20, 288-292.

- 1957a: Sedimentary characteristics of dust storms: III. Composition of suspended dust. Amer. J. Sci., 255, 206-213.

-, 1957b: Width of field strips to control wind erosion. Tech. Bull. 92, Kansas State College of Agriculture and Applied Science, 16 pp. 
-. , and N. P. Woodruff, 1954: Estimations of wind erodibility of field surfaces. J. Soil Water Conservation, 9, 257-265.

- , and -1957 : Sedimentary characteristics of dust storms: II. Visibility and dust concentration. Amer. J. Sci., 255, 104-114.

- , and - 1959: Estimations of wind erodibility of farm fields. Production Res. Rept. No. 25, U. S. Dept. of Agriculture, $21 \mathrm{p}$.

- , and -1963 : The physics of wind erosion and its control. Advances in Agronomy, Vol. 15, A. G. Norman, ed., New York, Academic Press, 301 pp.

Danielsen, E. F., 1964: Project Spring field Report. Defense Atomic Support Agency, 1517, $97 \mathrm{p}$.

El-Fandy, M. G., 1940: The formation of depressions of the Khamsin type. Quart. J. Roy. Meteor. Soc., 66, 323-335.

- 1953: On the physics of dusty atmospheres. Quart. J. Roy. Meteor. Soc., 79, 284-287.

Hidy, G. M., and J. R. Brock, 1970: An assessment of the global sources of tropospheric aerosols. To be published in Proc. Second Clean Air Congress, Washington, D. C., December 1970.

Jackson, M. L., 1958: Soil Chemical Analysis. New York, Prentice Hall, Inc., 498 pp.; sixth printing, 1970, by the author, Dept. of Soil Science, University of Wisconsin, Madison.
Judson, S., 1968: Erosion of the land-or what's happening to our continents? Amer. Scientist, 56, 356-374.

Priestley, C. H. B., 1959: Turbulent Transfer in the Lower Atmosphere. The University of Chicago Press, $130 \mathrm{pp}$.

Richards, L. A., 1949 : Methods of measuring soil moisture tension. Soil Sci, 68, 95-117.

Schuetz, L., 1971: Messung der Grossenverteilung von Luftgetragenem Staub und Bodenmaterial in der Libyschen Saharah. M.S. dissertation, Max-Planck Institut fuer Chemie (Otto-Hahn-Institut), Mainz, Germany.

Smalley, Ian J., 1970: Cohesion of soil particles and the intrinsic resistance of simple soil systems to wind erosion. $J$. Soil Sci., 21, 154-161.

Smith, H., and M. D. Weldon, 1949: A comparison of some methods for the determination of soil organic matter. Soil Sci. Soc. Amer. Proc., 5, 177-182.

U. S. Department of Agriculture Committee Report, 1962: A standardized procedure for residue sampling. U.S.D.A.-ARS, 41-68.

Walkley, A., 1947: A critical examination of a rapid method for determining organic carbon in soils-Effect of variations in digestion conditions and of inorganic soil conditions and of inorganic soil constituents. Soil Sci., 63, 251-264. 